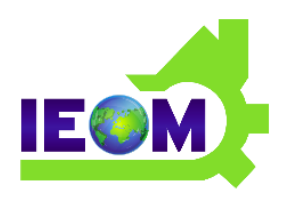

IEOM Society International

\section{International Journal of Industrial Engineering and Operations Management (IJIEOM) \\ Volume 2, No. 1, October 2020 \\ pp. $63-77$}

\title{
Carbon Emissions and Energy Balance in the Design of a Sustainable Food Waste Network
}

\author{
Adel W. Fadhel \\ Department of Systems Engineering \\ King Fahd University of Petroleum and Minerals \\ Dhahran, 31261, Saudi Arabia \\ adelfadhel@kfupm.edu.sa \\ Surendra M. Gupta \\ Department of Mechanical and Industrial Engineering \\ Northeastern University, 334 Snell Engineering Center, 360 Huntington Avenue \\ Boston, Massachusetts 02115 U.S.A. \\ s.gupta@northeastern.edu \\ https://doi.org/10.46254/j.ieom.20200105
}

\begin{abstract}
In this paper, the food waste valorization alternatives are evaluated from a sustainability point of view. Using food waste characteristics as input data, we estimate the sustainable benefits such as energy utilization and GHG emission reduction for each potential food waste processing technique. Additionally, the sustainable benefits of reverse logistics of food waste are quantified based upon geographic distance and valorization characteristics. We formulate the food waste network framework as a strategic linear programming (LP) model that aims to minimize total food waste management costs while satisfying emissions and energy use constraints. Given the recent regulations of the commercial food material disposal ban, we test the efficiency of the proposed framework by designing a sustainable food waste treatment network for the state of Massachusetts. Results show that with a marginal increase in the treatment cost of food waste, the model has achieved zero net emissions, zero net energy use, and a competitive overall sustainability impact. Thus, by utilizing the food waste network model, policymakers can achieve the best sustainable strategies for food waste management. The paper contributes theoretically to the assessment of the food waste recovery alternatives by expanding the system boundary and presenting additional key performance measures of sustainability. Practically, this study provides case studies based on real-life data and generates multiple scenarios to better analyze the results and select the best recovery options from a sustainability perspective.
\end{abstract}

ARTICLE INFO

\section{Introduction}

Sustainability is improving living standards not only for current society but also for future generations. It aims to balance the economic, environmental, and social impact of implementing supply chain goals in the long term. It incorporates objectives wider than just efficient and profitable production and consumption including socially fair and environmentally friendly products (Soysal et al. 2012). In the US, the food sector meets internal food security while providing support to the national economy. One important step in the journey of food products from farm to fork is the 
transportation and all related logistical processes to deliver food to the consumer. Improving the efficiency of these processes begin with designing a Food Supply Chain (FSC) network that considers the design of processing and distribution centers, the management of the cold chain, and the design of reverse logistics network (Li et al. 2014). These recent changes in FSC management goals have led to the development of the trending concept: Sustainable Food Supply Chain Management (SFSCM). As a result, new key performance indicators are developing that can capture the integrated triple bottom line of sustainability in which profit, people, and planet are working as drivers of the supply chain decisionmaking process (Soysal et al. 2012). The sustainability of the FSC is facing so many challenges. First, food insecurity presents in different parts of the world. In India for example, about $24 \%$ of families have days with no food at all (Li et al. 2014). At the same time, it is estimated that one-third of global food production is wasted per year (Gustavsson et al. 2011). Food production processes consume more than $10 \%$ of the total US energy budget, about $80 \%$ of freshwater in the US, and about $50 \%$ of U.S lands while more than $50 \%$ of all produced food is wasted before or after reaching consumers (Hall et al. 2009). This is estimated to cause a loss of more than $\$ 165$ billion, $25 \%$ of freshwater, and huge yearly losses of energy, lands, and other resources (Govindan et al. 2014). As new challenges have emerged such as climate change, fair trade, food waste, and food security, all different actors in the food industry should consider ways to produce, process, distribute and consume food more sustainably without compromising costs. Food industry stakeholders should develop decision-making models and set up standards and technologies that address the development of SFSCM (Li et al. 2014).

A related issue to the huge amount of wasted food is the increasing rates of global food insecurity. The United Nations' Food and Agriculture Organization (FAO) defines food security as the ability of all people, at all times, to have physical, social, and economic access to sufficient, safe, and nutritious food that meets their dietary needs and food preferences for an active and healthy life. The FAO estimated that more than 820 million people are undernourished in developing countries while about 15.7 million people are considered undernourished in developed countries (Thyberg 2015). Therefore, developing global policies and strategies of food waste prevention and recovery would be an effective sustainable approach towards addressing the food security issue (Fadhel et al. 2017). However, studies that addressed such issues and associated complexities are still insufficient (Garrone et al. 2014).

By examining the existing body of literature in the area of food waste management and recovery from a sustainability perspective, we notice that studies are insufficient and limited in terms of the lack of novel framework, subjective methodologies, or data-based results. The Availability-Surplus-Recoverability-Waste (ASRW) strategy developed by exploring $30 \mathrm{FSC}$ case studies is limited to the derived results of these studies and cannot be utilized for the development of the sustainable food systems in general (Garrone et al. 2014). Similarly, other studies drafted practical approaches from managerial propositions by investigating the causes of food waste in 15 commodities. However, such case-based methodologies would produce biased results that lack the generalization of data-based approaches (Mena et al. 2014). Other attempts to identify the effectiveness of the food waste recycling activities are based on comparative studies by considering regulatory variation in developed and developing countries. Such case studies are dependent on the geographic peculiarities and can only be valid within the region from which the information is derived (Thi et al. 2015). On the other hand, the framework of the food waste hierarchy approach is implied to prioritize food waste options. The priority in this approach is to work on food waste prevention, followed by directing food waste to human use, then animal feeding and composting, then comes the energy recovery from food waste, and lastly landfilling when all these options are exhausted. Although such a framework can consolidate the route through which the food waste stream could follow, it does not consider other important sustainability criteria to balance between those options. Also, this approach does not provide a methodology to implement food waste policies in practice (Papargyropoulou et al. 2014). Further, the food waste streamline can be observed in all stages of the FSC from farm to fork through production and distribution. However, relevant research studies only considered either the upper stream of food waste from farming and manufacturing or the lower stream from retailing and household and very limited studies on the simultaneous food waste throughout all stages of the FSC. Besides, such studies are interview-based foody waste policies that involve subjective bias and generalized results could not be derived (Gruber et al. 2016). Furthermore, studies aiming to develop efficient food waste management systems ignored developing data-based approaches that consider as many factors as possible such as carbon emissions and energy efficiency.

Therefore, our objective in this research is to overcome the limited approaches in the existing literature by proposing a novel comprehensive framework and a data-driven mathematical methodology that provide generalized and objective results and develop the sustainability of the food waste management throughout all the stages of the FSC. As such, we will study the closed-loop FSC sustainability in terms of food waste management that reduce its economic and environmental impact (Pochampally et al. 2008). The system boundaries include food waste resulted from farming, processing, packaging, warehousing, and distribution along with different disposal options to mitigate the food waste impact on sustainability. The model framework includes both local operational decisions and global strategic decisions. 
1. The first local decision is selecting the best food waste valorization options based on economic, environmental, and social conditions including energy use and Greenhouse Gas (GHG) emissions.

2. The global scaled decision includes network design and food waste distribution to and from valorization centers in a sustainable design context.

To this purpose, the framework address reducing food waste impact on sustainability by incorporating a sustainable food waste network (SFWN) model that optimizes economic and environmental tradeoffs.

\section{Literature Review}

Considering reverse material flow in the design of the SFSC network has been growing recently due to today's governmental regulations, customers' requirements, environmental concerns, and economic advantages (Fadhel and Gupta 2019). However, the research on closed-loop supply network design models in the food industry is very limited (Sgarbossa and Russo 2017). Further, issues related to the evaluation of the food waste reduction frameworks in terms of sustainability are not addressed in the literature and often not quantified (Schneider 2013).

\subsection{The Design for Sustainability}

Recently, the topic of designing SFSCM and developing efficient approaches to modeling complex food systems is of great interest to researchers. One example is a multi-objective model proposed by Kannan, Jafarian, and Khodaverdi for a two-echelon multi-vehicle location-routing problem for a sustainable supply of perishable foods (Govindan et al. 2014). Also, Qin, Qin and Wang propose a joint pricing approach for perishable food inventory control based on price sensitivity to demand and deterioration rates of quality and quantity (Qin et al. 2014). Bloemhof-Ruwaard and van der Vorst develop a decision support tool for minimizing carbon emission of food logistics networks at a minimum cost for a beef logistics chaincase (Soysal et al. 2014). Glover, Champion, Daniels, and Dainty apply institutional theory to analyze the role of supermarkets in supporting energy reduction in SFSC (Glover et al. 2014). Finally, Terry, Williams, and Ellram study the UK FSC to identify the causes of food waste (Mena et al. 2014). The study developed a framework of management practices that reduce waste in food multi-tier networks.

\subsection{The Network Modeling of the SFSC}

Network design and distribution processes play a significant role in the sustainability performance of FSCs due to increasing consumer demands for sustainable products, the scale of the food industry, the amount of food waste, and the impact of FSC on food security and global warming. Developing an effective design for a sustainable modern food distribution systems will ensure minimum GHG emissions and promote sustainability benefits for all SFSC stakeholders (Govindan et al. 2014). Lee and Tongarlak (2016) derived a retailer's optimal order policy under by-product synergy (BPS) that valorizes food waste from the main processes in the FSC to a useful input onto other secondary processes. Implementation of these BPS policies showed that food waste decreases when demand uncertainty and the tax benefit from the donation are low. Further, food donation can be induced by tax credit and disposal fees (Lee and Tongarlak 2016). Banasik et al. (2017) proposed a multi-objective model to optimize economic and environmental goals and investigate alternative recycling technologies organic matters for closing the loop in the mushroom supply chain. The study found that implementing recycling technologies could increase the total profit of the mushroom chain by $11 \%$, while the environmental indicator could improve by $28 \%$ (Banasik et al. 2017). Sgarbossa and Russo (2017) developed a new sustainable closed-loop supply chain (CLSC) model for best resource recovery and waste reduction practices, energy efficiency, and improved social development in the meat processing industry. By implementing the new model, the profitability index showed the viability of recovery plants, reduced global environmental impact, and new skilled positions that improved firm reputation in the social context (Sgarbossa and Russo 2017).

Garrone (2014) developed a food waste management strategy called Availability-Surplus-Recoverability-Waste (ASRW) in the context of the sustainable FSC. The study conducted 30 expletory case studies and presented three case studies to demonstrate the implementation of the proposed model (Garrone et al. 2014). Mena et al. (2014) investigated a multi-tier supply network of 15 food commodities in the UK to identify the underlining causes of food waste that lead to managerial propositions. Theses propositions trigger practical approaches to mitigate the economic, environmental, and social impact of food waste (Mena et al. 2014). Mirabella et al. (2014) provided a literature review on the recycling of solid and liquid waste from the food processing industry. The study presented the main uses of the derived resources and highlighted applications in the nutraceutical and pharmaceutical industry (Mirabella et al. 2014). Papargyropoulou et al. (2014) proposed a framework to identify food waste treatment options and priorities these options according to sustainability criteria by applying the waste hierarchy approach. The framework showed that the prevention of food waste is the most appealing sustainable option, then human use option, followed by recycling food waste into animal feed (Papargyropoulou et al. 2014). Thi et al. (2015) examined food waste management systems in developing countries with comparison to developed countries in terms of recycling activities, related regulations, and treatment technologies. 
The study provided a case study of Taiwanese food waste management system as a typical model for developing countries to follow (Thi et al. 2015). Gruber et al. (2016) explored societal, regulatory, and systematic factors that lead to food waste in the retail and wholesale sector by conducting interviews with store managers. Based on these factors, the study derived public policy strategies for managing food waste (Gruber et al. 2016). Balaji and Arshinder (2016) studied casual factors of food waste and interactions among them in emerging markets such as India by utilizing total interpretive structural modeling (TISM) and interviews with experts in the food industry. Findings showed that causes of food waste could be represented by 16 factors including lack of harvesting technology and increase of intermediate stages of the FSC (M and K 2016). Thyberg and Tonjes (2016) explored food waste drivers on the residential, institutional, and commercial levels in the US. Moreover, the study examined the impact of the food system modernization on food waste generation for the aim of developing a sustainable policy approach for effective food waste management (Thyberg and Tonjes 2016).

By analyzing the research area of the food waste sustainable recovery modeling, we observe the necessity to extend the conventional limited frameworks to the SFSCM including the network design of the sustainable food waste management. The limitations in the current research studies including but not limited to the absence of the sustainability parameters that estimate the economic, environmental, and social aspects of food waste management. In particular, there is no research analyzing the energy efficiency of the food waste recovery process. Second, there is no consideration of the various food waste valorization technologies and recovery options. Also, studies are limited to internal use of the food waste in a specific stage of the FSC and there is no analysis of the integrated recovery of the food waste both internally and to external supply chains (Lee and Tongarlak 2016). The implementation of encountered research is specific to certain food waste categories such as citrus or mushroom and cannot be generalized to the generic sustainable food waste management. Some research even does not consider food waste itself at all. Instead, it is only limited to the organic growing medium which is a very small portion of the wasted food amount (Banasik et al. 2017). Also, most of the research analysis is based on analytical approaches that do not consider the balance between the conflicting objectives of sustainability, to the contrary of the quantitative modeling approaches.

Consequently, we propose a comprehensive framework for a sustainable food waste recovery modeling that investigates the optimal configuration of the economic, environmental, social, and energy efficiency parameters. We adopt a quantitative modeling methodology to assess various food waste valorization alternatives based on the suggested sustainability criteria. The developed model is implemented in the case study of the Massachusetts food waste management system and results are verified by realistic data.

\section{Research Methodology}

Addressing the food waste reduction issue in the context of sustainable food systems requires a multidisciplinary approach to identify the intersection between valorization techniques, reverse supply chains, ecological, and social issues (Alqahtani et al. 2019). Implementing the proposed approach of the food waste network framework can be achieved through the following steps:

1. Defining the sustainable system boundaries.

2. Performing food waste assessment.

3. Analyzing food waste sustainable valorization benefits.

4. Solving the food waste network model.

\subsection{The Sustainable system boundaries}

The first step in developing the food waste reduction framework is to identify the characteristics of the wasted food accurately. Determining the best valorization option of food waste depends on the condition of the food in terms of type and quality, quantity, packaging characteristics, the source at which the waste occurred, energy and water use, and GHG emissions. These characteristics can be used to identify the system boundaries of food waste reduction. There are several different types of food waste including avoidable, non-avoidable, raw, processed, surplus food, and food waste. Accordingly, each type of food waste has certain shelf life properties and temperature control requirements. The quantity of food waste can be expressed in kg per capita per year or kcal per capita per day. The food waste may occur at any stage of the FSC from farm to fork. The distances between these sources and between the proposed valorization center locations are required to study the process of food waste reduction with tradeoffs between economic, environmental, and social costs (Gungor and Gupta 1999).

Moreover, reverse logistics parameters include locations of both suppliers and consumers, capacities, and transportation costs, and environmental properties such as energy use and GHG emissions (Gupta 2016). The food waste reduction framework utilizes the food waste and reverse logistics parameters as inputs for the food waste network model. 
Furthermore, the food waste hierarchy framework can be utilized to evaluate the sustainability impact of different food waste treatment options (See Figure 1). Papargyropoulou et al. (2014) proposed a framework to identify food waste treatment options and priorities these options according to sustainability criteria by applying the waste hierarchy approach (Papargyropoulou et al. 2014). The framework showed that prevention of food waste is the most appealing sustainable option, then human use option, next is recycling food waste into animal feed or by composting processes, followed by energy recovery (Papargyropoulou et al. 2014). The least favorable option according to this framework is the disposal of food waste into landfills due to the negative economic and environmental impact of this process.

\section{2 food waste valorization assessment}

In this step, the food waste valorization alternatives are evaluated from a sustainability point of view. These alternatives include Human use by donations or selling at the secondary market, recycling by preparing for animal feed or composting, and resource recovery by technologies such as anaerobic digestion. Each of these alternatives has a different impact on sustainability and a specific alternative or a combination of two or more could lead to the highest level of sustainable food waste reduction. Including reverse logistics modeling will ensure optimal utilization of the wasted food by minimizing the traveled distance. Figure 2 illustrates the different food waste valorization alternatives along with food waste and resources flows both within the internal FSC and in the external sustainable food system. We will focus on four processing options of food waste treatment based on the implementation feasibility of these options in the state of Massachusetts, USA.

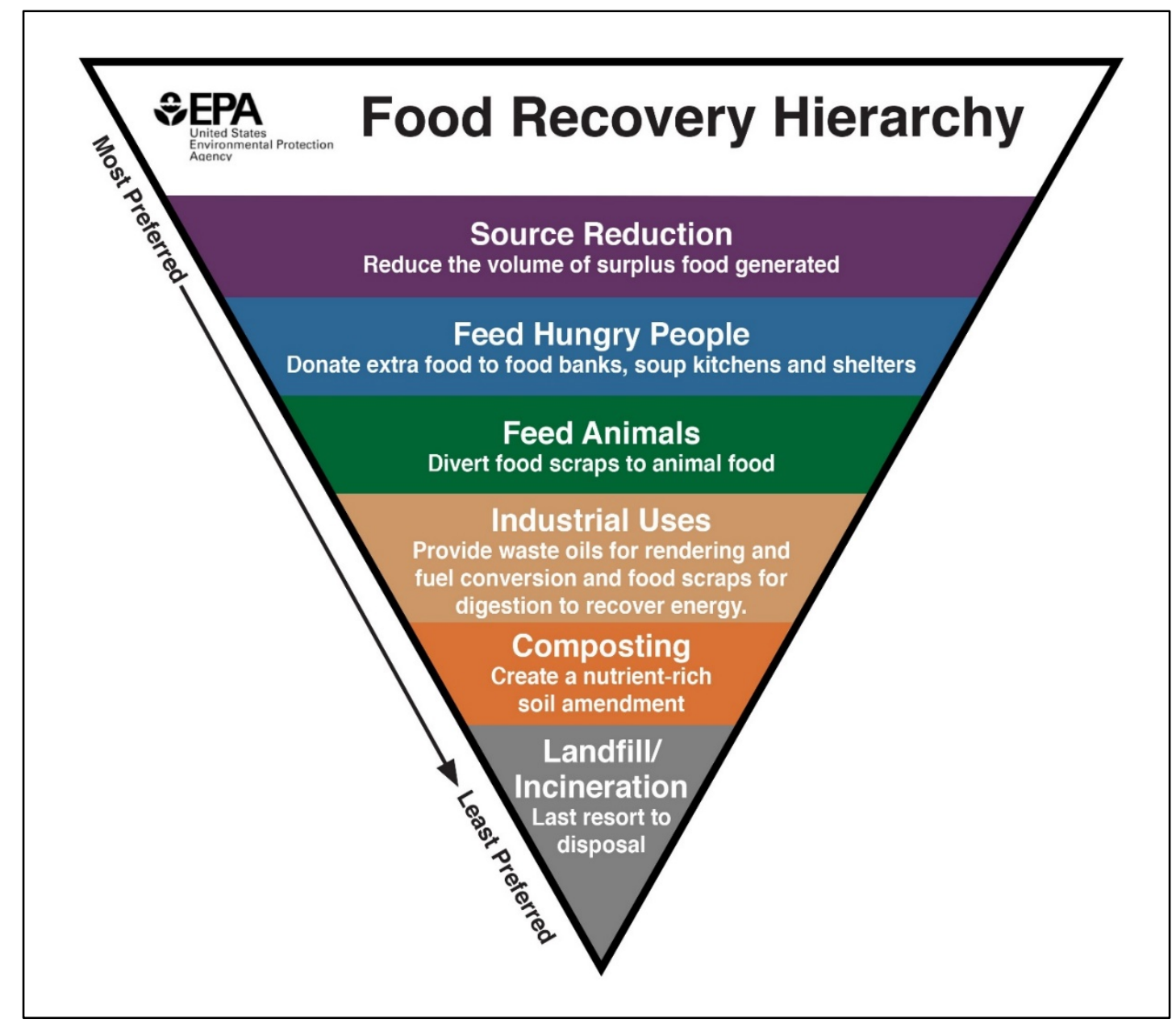

Figure 1. The Food Waste Hierarchy ('Food Recovery Hierarchy' 2019) 


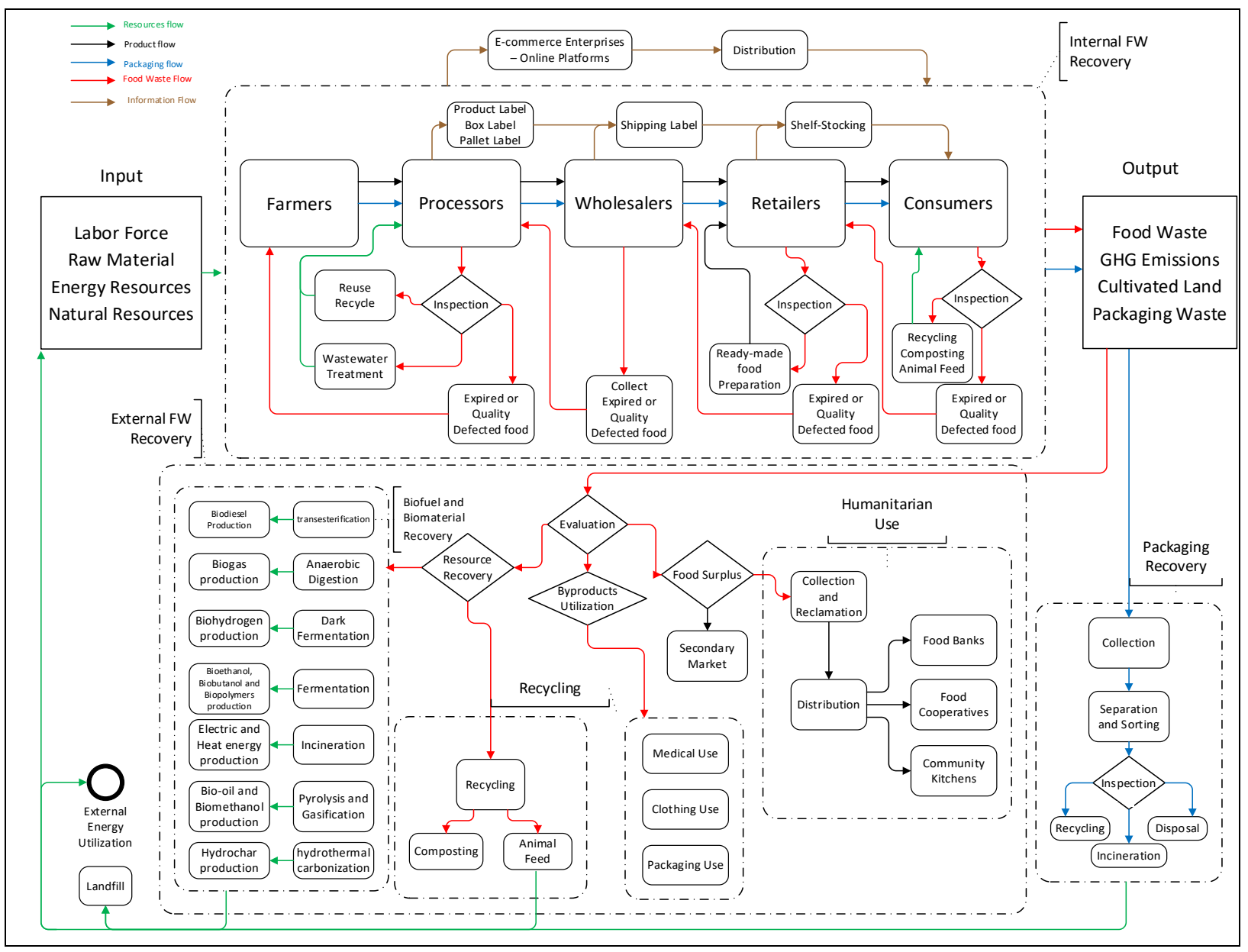

Figure 2. The Internal and external food waste valorization alternatives

\subsubsection{Humanitarian Relief}

Food surplus is avoidable food waste that is edible and can be used for human consumption under normal circumstances (Papargyropoulou et al. 2014). Hunger-relief organizations collect food surplus by cooperating with nodes of the SFSC and distribute the collected food to donation centers such as food banks, food cooperatives, and community kitchens. More than $10 \%$ of U.S. households who are affected by food insecurity receive nutritional assistance from federal programs such as Supplemental Nutrition Assistance Program (SNAP) and/or from charitable organizations such as food pantries (Thyberg 2015). To encounter household and community food insecurity, the utilization of food surplus appeared to be an efficient practice to improve food access to the vulnerable. Moreover, the UK government suggested that food surplus redistribution is a potential strategy in the context of sustainable food systems for reducing food waste and generating social, environmental, and economic benefits for the food industry (Midgley 2014).

\subsubsection{Animal Feed}

One processing technology of interest is to convert food waste into animal feed. Organic input to this process is exposed to initial inspection to remove large contaminants, then ground, run through additional contaminants removal, followed by dehydration or milling for mixing with other nutrients (DSM Environmental Services 2017).

\subsubsection{Composting}

FW often contains high concentrations of easily degradable organic substances such as sugars, starches, lipids, and proteins, thus it is suitable to be disposed of by composting (Chang and Hsu, 2008; Kumar et al., 2010). The inputs of the composting process include water, organic matter, and air while the outputs are carbon dioxide and compost that is used as fertilizer and soil enhancer. Although composting is not a new waste disposal method, the characteristics of food waste such as moisture content, nutrient content, and particle size still bring a unique challenge to the researchers, since the basic knowledge of FW composting is inadequate for supporting successful processes with high efficiency. Other 
important factors that influence the quality of the compost include temperature, aeration rate, and $\mathrm{pH}$ levels (Kocher 2018).

\subsubsection{Anaerobic Digestion}

Anaerobic digestion for biogas production (methane-rich gas) is a well-established technology perfectly suited for food waste management. This technology can be applied to almost all types of biodegradable substrates as source-separated organic fraction of municipal solid waste, agricultural or industrial food waste, and food manufacturing residues. The inputs to this process constitute food waste or any organic matter, energy, and water. The outputs include biogas that could be utilized for digester energy use, effluent, and digestate (Kocher 2018).

\subsection{Analyzing food waste sustainable valorization benefits}

Input data of different system factors are collected and analyzed to quantify the benefit of valorizing the food waste by a specific potential technique. A sustainable benefit model can be utilized to determine the food waste reduction potentials using input data within the system boundaries. Such models use food waste characteristic data to estimate sustainable benefits such as energy reduction and GHG emission reduction. Additionally, the sustainable benefits of reverse logistics of food waste are quantified based upon geographic distance, valorization characteristics, and technologies for collection, storage, and distribution. By identifying inputs, outputs, and externalities associated with the sustainable food waste reduction system, the following sets, and parameters for the food waste network problem are generated as shown in Table 1.

Table 1. Sets and parameters for the food waste network problem

\begin{tabular}{|c|c|}
\hline \multicolumn{2}{|l|}{ Sets } \\
\hline$g$ & $1, \ldots$, G Food Waste $(\mathrm{FW})$ generators \\
\hline$r$ & $1, \ldots, R$ FW recovery sites \\
\hline$v \in \mathcal{V}$ & $\begin{array}{l}\text { (Humanitarian Relief (HR), Secondary Market (SM), Animal Feed (AF), Composting (CO), By-Product } \\
\text { Production (BP), Anaerobic Digestion (AD), Transesterification (TR), Incineration (IN), Pyrolysis and } \\
\text { Gasification (PG), Hydrothermal Carbonization (HC), Landfill (LA)) }\end{array}$ \\
\hline \multicolumn{2}{|c|}{ Parameters } \\
\hline$d_{g r}$ & distance between FW generator $g$ and recovery site $r$ (mile) \\
\hline$t c_{g r v}$ & transportation cost between generator $\mathrm{g}$ and valorization option $v$ at recovery site $r(\$ /$ ton - mile $)$ \\
\hline $\mathrm{CO}_{2 \mathrm{rv}}$ & $\begin{array}{l}\text { carbon emissions/absorption resulting from establishing valorization option } v \text { in the recovery site } \\
r \text { (ton } \mathrm{CO}_{2} \text { eq/ton) }\end{array}$ \\
\hline $\mathrm{pCO}_{2 v}$ & carbon emission resulting from processing $\mathrm{FW}$ by option $v$ (ton $\mathrm{CO}_{2} \mathrm{eq} /$ ton) \\
\hline$t \mathrm{CO}_{2 g r v}$ & $\begin{array}{lllllllll}\text { carbon emissions resulting from transport between generator } \mathrm{g} \text { and option } v \text { in site } \\
r \text { (ton } \mathrm{CO}_{2} \mathrm{eq} / \text { ton }- \text { mile) }\end{array}$ \\
\hline$w_{r v}$ & energy required to establish option $v$ in site $r(\mathrm{kwh} /$ ton $)$ \\
\hline$p w_{v}$ & energy required to process FW with option $v$ ( $k w h /$ ton $)$ \\
\hline$t w_{g r v}$ & energy required for transport between generator $\mathrm{g}$ and option $v(\mathrm{kwh} /$ ton - mile $)$ \\
\hline$d b_{r}$ & development budget allocated for site $r(\$)$ \\
\hline$f c_{v}$ & fixed cost to establish option $v(\$ /$ ton $)$ \\
\hline$p c_{r v}$ & processing cost of FW by option $v$ in site $r(\$ /$ ton $)$ \\
\hline $\operatorname{cap}_{r v}$ & capacity of processing facility $\mathrm{v}$ in site $\mathrm{r}$ (ton) \\
\hline$c p_{g v}$ & capacity of generator $\mathrm{g}$ (ton) allocated to option $v$ \\
\hline$c p_{g}$ & total capacity of generator g (ton) \\
\hline$e w_{v}$ & power generation resulted from FW treatment by option $v$ ( $k w h /$ ton $)$ \\
\hline$e_{v}$ & conversion factor for carbon emission associated with power generation $\left(\right.$ ton $\left.\mathrm{CO}_{2} \mathrm{eq} / \mathrm{kwh}\right)$ \\
\hline$m_{v}$ & conversion factor for carbon emission associated with $\mathrm{FW}$ treatment $\left(\right.$ ton $\mathrm{CO}_{2} \mathrm{eq} /$ ton $)$ \\
\hline$f d_{v}$ & sustainability threshold for recovered FW by option $v($ ton $)$ \\
\hline $\max$ & maximum disposal limit of food waste (ton) \\
\hline
\end{tabular}

\subsection{The Food waste network model}

We formulate the food waste network framework as a strategic linear programming (LP) model that aims to minimize total food waste management costs while satisfying emissions and energy use constraints. The formulation is based on the following assumptions: 
1. One year of food waste treatment with long term use of treatment options. This is because establishing treatment facilities requires substantial time and resources, which makes short term switching infeasible.

2. The food waste is assumed to be separated at the source and ready to be collected by the hauler.

3. The landfill does not involve gas recovery units.

4. Assume expansion of existing food waste recycling facilities.

5. Assume the life cycle of the treatment facility is 20 years.

Given the sets and parameters in Table 1, the food waste network model is formulated as follows.

Decision Variables

Table 2. The model decision variables

\begin{tabular}{|l|l|}
\hline$x_{r v}$ & $\left\{\begin{array}{l}1, \text { if valorization option } v \text { is to be opened in site } r \\
0, \text { otherwise }\end{array}\right.$ \\
\hline$y_{g r v}$ & FW flow between generator $g$ and recovery site $\mathrm{r}$ allocated to valorization option $\mathrm{v}($ ton $)$ \\
\hline
\end{tabular}

Table 2 shows the decision variables of the food waste network model.

Objective function

$$
\begin{aligned}
& \min \sum_{r=1}^{R} \sum_{v \in \mathcal{V}} f c_{v} x_{r v} c a p_{r v}+\sum_{g=1}^{G} \sum_{r=1}^{R} \sum_{v \in \mathcal{V}} d_{g r} t c_{g r v} y_{g r v}+ \\
& \sum_{g=1}^{G} \sum_{r=1}^{R} \sum_{v \in \mathcal{V}} p c_{r v} y_{g r v}
\end{aligned}
$$

The objective function (1) minimizes the fixed, transportation, and processing cost of the food waste treatment. The fixed cost represents establishing treatment facilities. The transportation cost is related to transporting food waste by truck from generators to treatment facilities. The processing cost is associated with all activities of food waste treatment by the designated facilities.

Demand fulfillment constraint

$$
\begin{array}{ll}
\sum_{g=1}^{G} \sum_{r=1}^{R} y_{g r v} \geq f d_{v} & \forall v \in \mathcal{V} \\
\sum_{r=1}^{R} y_{g r v} \leq \max _{L A} & \forall g: 1, \ldots, G, v: \text { LA }
\end{array}
$$

The set of constraints (2) guarantee that the demand of each food waste recovery product is met. Constraint (3) limits the food waste disposal amount to a maximum value set by regulators.

Capacity constraints

$$
\begin{array}{ll}
\sum_{g=1}^{G} y_{g r v} \leq x_{r v} c a p_{r v} & \forall r: 1, \ldots, R, v \in \mathcal{V} \\
\sum_{r=1}^{R} y_{g r v} \leq c p_{g v} & \forall g: 1, \ldots, G, v \in \mathcal{V}
\end{array}
$$

Constraints (4) and (5) limit the flow of food waste from generators to treatment sites per the processing capacity of treatment facilities and generators capacities allocated to each treatment facility, respectively.

Flow balance constrains

$$
\sum_{r=1}^{R} \sum_{v \in V} y_{g r v}=c p_{g} \quad \forall g: 1, \ldots, G
$$

$\sum_{r=1}^{R} \sum_{v \in V} x_{r v} c a p_{r v} \geq \sum_{g=1}^{G} c p_{g}$

Constraint (6) force the amount of food waste flow within the system to be equal to the total capacity for each generator. Constraint (7) ensures the capacity of all food waste treatment facilities is at least as much as the total capacity of all generators.

Development budget constraint

$$
\sum_{v \in V} f c_{v} x_{r v} c a p_{r v} \leq d b_{r} \quad \forall r: 1, \ldots, R
$$

Constraint (8) limits the fixed cost to establish treatment sites per the available budget for each site.

Emissions control constraint

$$
\begin{aligned}
& \sum_{g=1}^{G} \sum_{r=1}^{R} \sum_{v=L A} m_{\mathrm{v}} y_{g r v}+\sum_{g=1}^{G} \sum_{r=1}^{R} \sum_{v \in \mathcal{V}} p C O_{2 v} y_{g r v}+\sum_{g=1}^{G} \sum_{r=1}^{R} \sum_{v \in \mathcal{V}} d_{g r} t C O_{2 g r v} y_{g r v}+ \\
& \sum_{r=1}^{R} \sum_{v \in \mathcal{V}} C_{2 r v} x_{r v} \operatorname{cap}_{r v} \leq \sum_{g=1}^{G} \sum_{r=1}^{R} \sum_{v \in \mathcal{V}-\{\mathrm{LA}\}} m_{v} y_{g r v}+\sum_{g=1}^{G} \sum_{r=1}^{R} \sum_{v \in\{\mathrm{AD}, \mathrm{TR}, \mathrm{IN}, \mathrm{PG}, \mathrm{HC}\}} e_{v} e w_{v} y_{g r v}
\end{aligned}
$$

Constraint (9) controls the net emissions resulting from the food waste treatment system. It ensures that emissions associated with establishing treatment facilities plus emissions from landfilling, processing, and transportation of food waste must either be offset by diverting food waste from disposal to landfill or food waste used for energy recovery. 
Energy control constraint

$\sum_{g=1}^{G} \sum_{r=1}^{R} \sum_{v \in \mathcal{V}} p w_{v} y_{g r v}+\sum_{g=1}^{G} \sum_{r=1}^{R} \sum_{v \in \mathcal{V}} d_{g r} t w_{g r v} y_{g r v}+\sum_{r=1}^{R} \sum_{v \in \mathcal{V}} w_{r v} x_{r v} c a p_{r v} \leq$

$\sum_{g=1}^{G} \sum_{r=1}^{R} \sum_{v \in\{\mathrm{AD}, \mathrm{TR}, \mathrm{IN}, \mathrm{PG}, \mathrm{HC}\}} e w_{v} y_{g r v}$

Like constraint (9), Constraint (10) ensures that the energy supply to the food waste treatment system is provided by the energy recovered from the food waste treatment activities.

$x_{r v} \in\{0,1\}, y_{\text {grv }} \geq 0 \quad \forall r: 1, \ldots, R, v \in \mathcal{V}, g: 1, \ldots, G$

Finally, constraint (11) enforces binary values and non-negativity for the decision variables.

\section{Designing the Food Waste Network in Massachusetts}

We test the efficiency of the proposed framework by designing a sustainable food waste treatment network for the state of Massachusetts. The total amount of food waste in Massachusetts is estimated to be over one million tons generated from the commercial sector that include food producers, retailers, restaurants, hospitals, and other institutions. Although the wasted food has the potential to be diverted for human use, recycling, or energy recovery, most of the waste is disposed of in landfills. This practice is impacting the environment negatively by increasing GHG emissions from landfills (Ilgin and Gupta 2010). As a result, the Massachusetts department of environmental protection (MassDEP) initiated a commercial food material disposal ban. The ban that took effect in 2014, limits the amount of commercial organic waste by businesses and institutions to a maximum of one ton per week (ICF 2016). This regulation is considered as one of the agency's initiatives to achieve a 35\% food waste diversion from disposal by 2020 (Gerlat 2014).

\section{Data Collection and Analysis}

Table 3 shows the average capacity for all food waste generators in Massachusetts to divert their food waste using four currently available processes. These processes are Human use, animal feed, composting, and anaerobic digestion. To comply with the ban, the capacity of disposal is limited to 600,000 tons of food waste.

Table 3. The capacity of FW generators in Massachusetts (ICF 2016)

\begin{tabular}{|l|l|l|l|l|l|}
\hline \multirow{2}{*}{$\begin{array}{l}\text { The total capacity of FW for } \\
\text { all generators } c p_{g} \text { (ton) }\end{array}$} & \multicolumn{5}{|l|}{ Capacity for Food Waste to be diverted by process $v c p_{\text {gv }}$ (ton) } \\
\cline { 2 - 6 } & HR & AF & CO & AD & LA \\
\hline $1,000,000$ & 400,000 & 700,000 & 700,000 & 800,000 & $1,000,000$ \\
\hline
\end{tabular}

We have collected emission, energy, and demand parameters data for each of the five potential processes that could be selected for food waste treatment. Transportation cost for humanitarian relief is higher than other treatment processes as food need more temperature control equipment to be transported safely (Kocher 2018). Carbon emissions cost is based on estimated emissions resulted from processing food waste by a particular process divided by the emissions social cost which is estimated to be $38 \$$ per ton $\mathrm{CO}_{2}$ eq (Industrial Economics 2017). We calculated the transportation emission and energy based on using truck mode (Weber and Matthews 2008). Fixed costs include site preparation to expand processing activities and equipment purchases (DSM Environmental Services 2017). Processing cost includes operational costs, maintenance, and labor cost to process food waste per ton (DSM Environmental Services 2017). The energy required to process a ton of food waste by composting is the highest compared to other processing options. On the other hand, processing food waste by landfill disposal consumes the lowest energy rates (Salemdeeb et al. 2017a). We deployed a conversion factor to calculate emissions resulted from food waste disposal in the Landfill. The data analysis is summarized as shown in Table 4. MassDEP has selected four sites for potential expansion to meet the expected increase in food waste diversion. We have derived the coordination of the average location of all generators in Massachusetts (DSM Environmental Services 2017). Accordingly, the distance from this central location to each potential processing site is calculated as shown in Table 5. Moreover, we derived the estimated budget allocated for each processing site from MassDEP relevant reports.

Table 4. Data analysis summary for the FW network problem

\begin{tabular}{|l|l|l|l|l|l|l|l|l|l|l|l|l|l|}
\hline $\begin{array}{l}\text { Option } \\
v\end{array}$ & $t c_{g r v}$ & $C O_{2 r v}$ & $p C O_{2 v}$ & $t C O_{2 g r v}$ & $w_{r v}$ & $p w_{v}$ & $t w_{g r v}$ & $f c_{v}$ & $p c_{r v}$ & $e w_{v}$ & $e_{v}$ & $m_{v}$ & $\begin{array}{l}f d_{v} \\
\times 1000\end{array}$ \\
\hline $\mathrm{HR}$ & 0.915 & 0.060 & 0.020 & 0.0003 & 123 & 141 & 1.22 & 75 & 16 & - & - & 1.02 & 150 \\
\hline $\mathrm{AF}$ & 0.500 & 0.270 & 0.090 & 0.0003 & 450 & 133.6 & 1.22 & 75 & 18 & - & - & 1.02 & 100 \\
\hline $\mathrm{CO}$ & 0.500 & 0.600 & 0.200 & 0.0003 & 435 & 145 & 1.22 & 80 & 8.4 & - & - & 1.02 & 100 \\
\hline $\mathrm{AD}$ & 0.500 & 0.189 & 0.063 & 0.0003 & 330 & 110 & 1.22 & 90 & 33 & 550 & $3.4 \mathrm{E}-04$ & 1.02 & 50 \\
\hline $\mathrm{LA}$ & 0.500 & 0.840 & 5.600 & 0.0003 & 180 & 60 & 1.22 & 50 & 3 & - & - & 1.02 & - \\
\hline
\end{tabular}




\section{Results}

By implemented the collected data of different parameters, we run the food waste network model in Lingo and obtain an optimal solution in less than $0.1 \mathrm{~s}$ on a computer configured with an Intel Core $3.3 \mathrm{GHz}$ processor and $8 \mathrm{~GB}$ of RAM. To compare the results, we make three different scenarios of the model. First, we make no restrictions either on the net emissions of GHG or on the net power consumption of the system. This is achieved by relaxing constraints 9 and 10 , which will show the purely economic perspective of the optimization model. Second, we employ constraint 9 that requires offset of the resulted emissions by a sustainable treatment of the food waste. Lastly, the third scenario is to make the food system self-sufficient in terms of energy in addition to mitigating the resulted emissions. This is achieved by enforcing both constraints 9 and 10. The results are summarized in Table 6 along with different KPIs to measure the sustainability impact of each scenario. The main KPIs include the cost of food waste treatment, net mitigated emissions, net energy use per ton of valorized food waste, and the food waste hierarchy impact. Figure 3 shows the results of the FW network represented in the spider chart.

Table 5. Distance from generators to potential processing sites (ICF 2016)

\begin{tabular}{|l|l|l|}
\hline Site $r$ & Distance to generators $d_{g r}$ (mile) & Development Budget $d b_{r}$ (million $\$$ ) \\
\hline 1 & 65.50 & 28.50 \\
\hline 2 & 82.60 & 67.00 \\
\hline 3 & 22.60 & 71.75 \\
\hline 4 & 39.70 & 44.25 \\
\hline
\end{tabular}

Table 6. Results and sustainability KPIs of the FW network model

\begin{tabular}{|c|c|c|c|c|c|}
\hline & Scenario 1 & \multicolumn{2}{|c|}{ Scenario 2} & \multicolumn{2}{|c|}{ Scenario 3} \\
\hline Total Cost & $88,294,350.00$ & $\$$ & $114,264,400.00$ & $\$$ & $118,579,400.00$ \\
\hline Food Treatment cost per ton & 88.29 & $\$$ & 114.26 & $\$$ & 118.58 \\
\hline Fixed Cost & $62,500,000.00$ & $\$$ & $80,250,000.00$ & $\$$ & $82,000,000.00$ \\
\hline Fixed Cost Per ton & 62.50 & $\$$ & 80.25 & $\$$ & 82.00 \\
\hline Transportation Cost & $16,554,350.00$ & $\$$ & $17,634,350.00$ & $\$$ & $16,989,350.00$ \\
\hline Transportation Cost per ton & 16.55 & $\$$ & 17.63 & $\$$ & 16.99 \\
\hline Processing Cost & $9,240,000.00$ & $\$$ & $16,380,000.00$ & $\$$ & $19,590,000.00$ \\
\hline Processing Cost per ton & 9.24 & $\$$ & 16.38 & $\$$ & 19.59 \\
\hline Food Treatment Carbon Impact & 3221346.09 & 0. & & 0. & \\
\hline Food Treatment Carbon Impact per ton & 3.22 & 0. & & 0. & \\
\hline Food Energy Use impact & 103650974 & & 6872 & 0. & \\
\hline Food Energy Use impact per ton & 103.65 & & & 0. & \\
\hline Food waste hierarchy impact & $44.05 \%$ & & & & $1 \%$ \\
\hline
\end{tabular}

In the case of scenario one, the treatment cost is low, but energy consumption and emissions are relatively high. The total cost per ton reads $\$ 88.29$ but emitting 3.22 ton $\mathrm{CO}_{2} \mathrm{eq} /$ ton and consuming energy equivalent to $103.65 \mathrm{kwh} /$ ton. On the other hand, the treatment cost has increased to $\$ 114.26$ in scenario 2 as a result of diverting more food waste from disposal to landfill. However, this scenario achieved zero net emissions and the recovery of energy that reduce energy consumption by $\% 38$. Moreover, with just a 3.8\% increase in the treatment cost compared to scenario 2, scenario 3 has achieved zero net emissions and zero net energy use. However, this scenario has treated more food waste by anaerobic digestion and diverted from human use. As a result, the score for food waste hierarchy is lower than scenario 2 but higher than scenario 1. Further, in terms of the quantitative evaluation criteria for the food waste reduction measures, the results show that the model achieved the optimal balance between the effectiveness of diverting all the amount of food waste from landfill disposal and the efficiency of maximizing the sustainable impact of such diversion (Goossens et al. 2019). Therefore, comparing all scenarios shows that planning and designing the food waste network model is vital to reach the balance between different parameters of the system and to better use of resources. These derived results are based on the data entered for the food waste characteristics and other parameters. In case of any changes to these data, the results will change accordingly. For example, if the food waste is not edible and contains a large amount of contaminates, then energy recovery treatment options are more appropriate than human use or animal feed. In this case, achieving zero net emissions and zero net energy use would be more easily and less costly.

\section{Discussion}

Our study demonstrates a new approach to the sustainable modeling of the food waste recovery network. In particular, we built a quantitative evaluation of sustainable food waste treatment concerning economic, environmental, and social implications. The economic performance shows that shifting the food waste into the higher levels of the food waste 
hierarchy will result in moderate processing costs. Other studies in the literature that consider human use as a factor that contributes to food waste through the incentives of donation tax credits. In contrast, we assume that the human use of food waste is a contributing factor to sustainable development in the context of the food waste network and our results validate such assumption. Similar case studies in literature only considered the food waste to be recovered within the internal FSC which results in balancing profitability to the environmental performance of the recycling technologies. However, we extend this approach by considering the opportunity of food waste treatment in external supply chains which result in additional costs. Given this assumption, our model shows superior results by achieving energy selfsufficiency and $100 \%$ improvement in terms of environmental performance which is measured by the net carbon emissions. By investigating similar case studies of analyzing the food waste treatment in the state of Massachusetts, we observe that such studies only consider two combinations of the three sustainability parameters such as the socioeconomic dimensions (Kocher 2018). While these studies emphasized the cost-benefit analysis in evaluating the food waste treatment options, our study extended the model to incorporate the network design of the process. Further, the proposed food waste recovery network incorporates multiple parameters to evaluate the optimality of the outcomes, given the carbon emission and energy use constraints, rather than the single cost-benefit measure. Therefore, the presented model extends the theoretical framework of the food waste treatment by combining multi-dimensional sustainability measures and suggests a technical tool for the optimal selection of food waste treatments.

The food waste network model is a valuable tool that policymakers, generators, and processors can use to determine the best sustainable food waste management. The model incorporates data about food waste to address the tradeoffs between the cost of treatment, environmental impact, resource utilization, and social impact derived from the food hierarchy framework. Moreover, the model largely depends on the advancement of food waste separation and treatment techniques. As these techniques improve, the treatment of food waste will be more efficient which will result in increased energy recovery, reduced emissions, and minimized treatment costs. The model metrics and KPIs enables decision-makers to manage the food waste treatment from a holistic sustainable perspective. First, the treatment cost KPI enables investors to make a cost-benefit analysis and determine the economic viability of different treatment options. Second, the treatment emissions impact is crucial to comply with environmental policies relevant to climate change mitigation. Third, the energy use impact enables all stakeholders to cut back on fossil fuel dependency that has fluctuated prices and severe environmental impact. The food hierarchy impact adds more value to the society by allowing more food to be distributed to the most vulnerable sectors and amplify the public good consequently. Thus, by combining all these indicators in the food waste network model, policymakers can achieve the best sustainable strategies for food waste management.

\subsection{The Social Implication}

Incorporating the food waste hierarchy impact measure in the model allowed policymakers to select a combination of recovery options that divert more food to human use to encounter household and community food insecurity. More than $10 \%$ of U.S. households who are affected by food insecurity receive nutritional assistance from federal programs such as Supplemental Nutrition Assistance Program (SNAP) and/or from charitable organizations such as food pantries (Davis et al. 2014). The model results showed that in scenario 2,35\% of the targeted food waste was utilized for human use which increased the total sustainability index to $80.71 \%$. Moreover, $25 \%$ of the total food waste was processed for animal feed supply that replaces the huge resources needed for the production of raw animal feed. Recycling food waste as pig feed in the EU would provide the required feed amount to supply $20 \%$ of EU pork production which leads to reduce land use of EU pork by 1.8 million hectares of farmland (Salemdeeb et al. 2017b).

Further, all the food waste was diverted from landfill disposal in scenarios 2 and 3 which results in a reduction of the adverse social impact by air pollution. Another public health benefit is to minimize the health risks posed by the concentration of hazardous substances from the food waste landfilling process. Such a process produces an increased amount of heavy metal content which impacts human health adversely (Nakakubo et al. 2012). The food waste hierarchy index provides an insight into the public health risk assessment. Scenario 1 has the worst impact on human health in this concern compared to scenarios 2 and 3. 


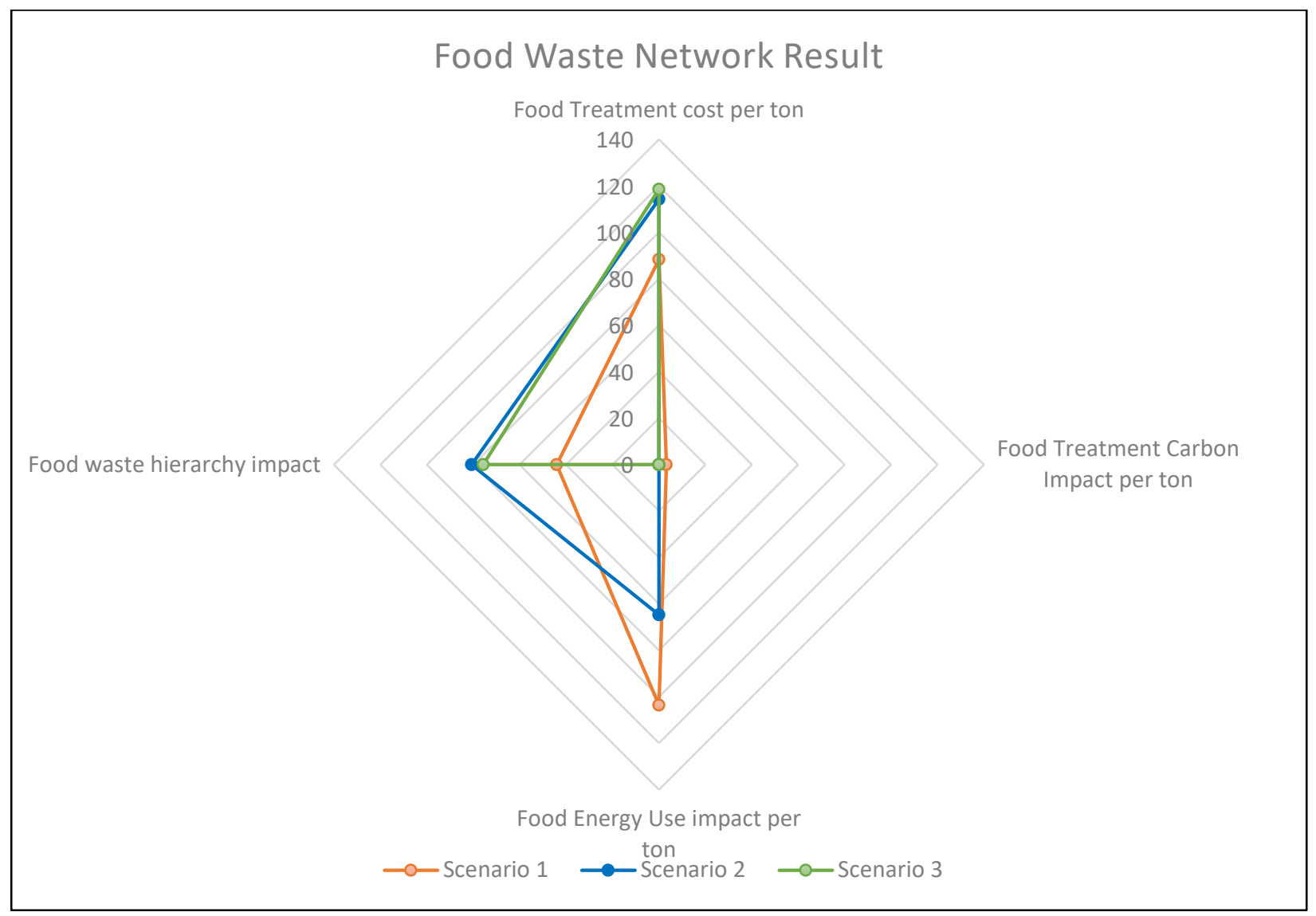

Figure 3. Spider chart of the FW network results

\subsection{Comparison of the SFWN model to the ASRW model}

The multifaceted concept of food waste recovery from a sustainability perspective was addressed in multiple case studies by presenting a model of surplus food generation and management, called Availability-Surplus-Recoverability-Waste (ASRW) (Garrone et al. 2014). The ASRW model distinguishes between different surplus food's Degree of Recoverability (DoR) where feeding human has the highest DoR, followed by feeding animals, waste recovery, and waste disposal has the least DoR. Determining the DoR is based on the intrinsic recoverability (IR) and the required management intensity (MI) of surplus food. The ASRW framework was applied to three case studies of food manufacturers, retailers, and service companies in the Italian market. In each case study, the food waste sources were analyzed, and treatment options were evaluated based on the conceptual ASRW to determine the food waste at the social level. In contrast to our approach which gives more flexibility for policymakers to choose from different options, the ASRW model only evaluates the pre-determined treatment options based on managerial decisions. Consequently, that model does not provide comparative analysis and optimization of the different food waste treatment options. Moreover, the selection of food waste treatment options presented in these case studies was based on the availability of such options. However, unlike our analysis which only consider the available options, the results of the ASRW approach is vulnerable to the changes in the food waste treatment services. Further, the categorization of food waste to social level by the ASRW model is restricting the broad concept of sustainability that balance not only the social level but also the economic and environmental perspectives as shown in our model (Garrone et al. 2014).

\section{Conclusion}

This paper proposed a novel quantitative food waste network model underpinned by a multi-dimensional approach that balances economic, environmental, social, and resource utilization goals. As such, the study transformed the analytical framework of food waste recovery hierarchy into a practical decision-making policy in the context of sustainable food waste networks. Further, the adopted research methodology incorporated uncovered aspects in the current literature in terms of considering food waste treatment both in the internal FSC and to external systems, simultaneously.

Our literature review indicates that there is a lack of research on the sustainable food waste network about issues such as considering the various food waste recovery options and technologies, optimizing the food waste recovery network, and 
the inclusion of key sustainability parameters. For this purpose, we formulated the problem as a linear programming model that minimizes total treatment cost given constraints imposed by different stakeholders of the sustainable food waste management system. Moreover, we derived a set of metrics that enables policymakers to move towards a more sustainable food waste management. The model is implemented on designing the food waste network of the state of Massachusetts, USA. The results showed the potential of achieving higher sustainability performance of the food waste recovery process under budget constraints. Food producers, distributors, and consumers may utilize this model to tackle logistical issues of food waste recovery with a more efficient and sustainable structure. The theoretical contribution of the study is manifested by the assessment of the food waste recovery alternatives through expanding the system boundary and presenting additional key performance measures of sustainability. In practice, this study provides case studies based on real-life data and generates multiple scenarios to better analyze the results and select the best recovery options from a sustainability perspective.

This research can be further extended, and future work can be built on it in multiple directions. One could be to extend the KPIs to include more environmental measures such as air pollution impact or social measures such as public health impact and employment rate impact. Also, the design of a more aligned conceptual model on which assessment criteria to consider and how to optimize the associated sustainability parameters would give more insight into which actions are most promising in terms of food waste reduction. Another direction is to incorporate not only food waste but also packaging and other waste streams to the model to study the interdependency between all of them. Including more parameters and KPIs suggest the problem to be analyzed by the multi-criteria decision-making techniques. Moreover, future research could be conducted by implementing different datasets to the model. The area of food waste prevention could also be investigated in terms of the efficiency of food distribution to consumers given food system resilient conditions. Finally, this research shows that there is a need to design food waste management models that address complex issues in the development of sustainable food systems.

\section{Conflict of interest}

The authors declare that they have no conflict of interest.

\section{References}

Alqahtani, A. Y., Kongar, E., Pochampally, K. K., and Gupta, S. M., Ed.^Eds. Responsible Manufacturing: Issues Pertaining to Sustainability, ed. (no.). CRC Press, p.^pp., 2019.

Banasik, A., Kanellopoulos, A., Claassen, G. D. H., Bloemhof-Ruwaard, J. M., and van Der Vorst, J. G. A. J., "Closing loops in agricultural supply chains using multi-objective optimization: A case study of an industrial mushroom supply chain," International Journal of Production Economics, vol. 183, no. PB, pp. 409-20, 2017.

Davis, L. B., Sengul, I., Ivy, J. S., Brock, L. G., and Miles, L., "Scheduling food bank collections and deliveries to ensure food safety and improve access," Socio-Economic Planning Sciences, vol. 48, no. 3, pp. 175-88, 2014/09/01/ 2014.

DSM Environmental Services, I., ANALYSIS OF ORGANICS DIVERSION ALTERNATIVES.2017

Fadhel, A. W., and Gupta, S. M. "Recent Research Trends in the Sustainable Food Supply Chain Management." In the 2019 Annual Meeting of the Northeast Decision Sciences Institute, 852-64. Philadelphia, Pennsylvania. 2019.

Fadhel, A. W., Ndiaye, M., Khumawala, B., and Gupta, S. M. "Waste Management in Sustainable Food Supply Chain through Reverse Logistics." In the 2017 Annual Meeting of the Northeast Decision Sciences Institute, 1091-100. Springfield, Massachusetts. 2017.

'Food Recovery Hierarchy'. 2019. United States Environmental Protection Agency. https://www.epa.gov/sustainablemanagement-food/food-recovery-hierarchy.

Garrone, P., Melacini, M., and Perego, A., "Opening the black box of food waste reduction," Food policy, vol. 46, pp. 129-39, 2014.

Gerlat, A., "Massachusetts to Ban Some Commercial Food Waste," Waste360 (Online), 2014.

Glover, J. L., Champion, D., Daniels, K. J., and Dainty, A. J. D., "An Institutional Theory perspective on sustainable practices across the dairy supply chain," International Journal of Production Economics, vol. 152, pp. 102-11, 2014/06/01/ 2014.

Goossens, Y., Wegner, A., and Schmidt, T., "Sustainability Assessment of Food Waste Prevention Measures: Review of Existing Evaluation Practices," (in English), Systematic Review, vol. 3, no. 90, 2019-October-10 2019.

Govindan, K., Jafarian, A., Khodaverdi, R., and Devika, K., "Two-echelon multiple-vehicle location-routing problem with time windows for optimization of sustainable supply chain network of perishable food," International Journal of Production Economics, vol. 152, pp. 9-28, 2014/06/01/ 2014.

Gruber, V., Holweg, C., and Teller, C., "What a waste! Exploring the human reality of food waste from the store manager's perspective.(Report)," vol. 35, no. 1, p. 3, 2016.

Gungor, A., and Gupta, S. M., "Issues in environmentally conscious manufacturing and product recovery: a survey," Computers \& Industrial Engineering, vol. 36, no. 4, pp. 811-53, 1999. 
Gupta, S. M., Ed.^Eds. Reverse supply chains: issues and analysis, ed. (no.). CRC Press, p.^pp., 2016.

Gustavsson, J., Cederberg, C., Sonesson, U., Van Otterdijk, R., and Meybeck, A., "Global food losses and food waste," Food and Agriculture Organization of the United Nations, Rom, 2011.

Hall, K. D., Guo, J., Dore, M., and Chow, C. C., "The progressive increase of food waste in America and its environmental impact," PloS one, vol. 4, no. 11, p. e7940, 2009.

ICF, "massachusetts commercial food waste ban Economic Analysis."2016

Ilgin, M. A., and Gupta, S. M., "Environmentally conscious manufacturing and product recovery (ECMPRO): A review of the state of the art," Journal of Environmental Management, vol. 91, no. 3, pp. 563-91, 2010.

Industrial Economics, I., "Benefit-Cost Analysis of Potential Food Waste Diversion Legislation."2017

Kocher, N., "Cost Benefit Analysis of Food Waste Processing in Massachusetts," 2018

Lee, D., and Tongarlak, M. H., "Converting retail food waste into by-product," European Journal of Operational Research, 2016.

Li, D., Wang, X., Chan, H. K., and Manzini, R., "Sustainable food supply chain management," International Journal of Production Economics, vol. 152, pp. 1-8, 2014/06/01/ 2014.

M, B., and K, A., "Modeling the causes of food wastage in Indian perishable food supply chain," Resources, Conservation \&amp; Recycling, vol. 114, pp. 153-67, 2016.

Mena, C., Terry, L. A., Williams, A., and Ellram, L., "Causes of waste across multi-tier supply networks: Cases in the UK food sector," International Journal of Production Economics, vol. 152, pp. 144-58, 2014/06/01/ 2014.

Midgley, J. L., "The logics of surplus food redistribution," Journal of Environmental Planning and Management, vol. 57, no. 12, pp. 1872-92, 2014/12/02 2014.

Mirabella, N., Castellani, V., and Sala, S., "Current options for the valorization of food manufacturing waste: a review," Journal of Cleaner Production, vol. 65, pp. 28-41, 2/15/2014.

Nakakubo, T., Tokai, A., and Ohno, K., "Comparative assessment of technological systems for recycling sludge and food waste aimed at greenhouse gas emissions reduction and phosphorus recovery," Journal of Cleaner Production, vol. 32, pp. 157-72, 2012.

Papargyropoulou, E., Lozano, R., K. Steinberger, J., Wright, N., and Ujang, Z. b., "The food waste hierarchy as a framework for the management of food surplus and food waste," Journal of Cleaner Production, vol. 76, pp. 106$15,8 / 1 / 2014$.

Pochampally, K. K., Nukala, S., and Gupta, S. M., Ed.^Eds. Strategic planning models for reverse and closed-loop supply chains, ed. (no.). CrC Press, p.^pp., 2008.

Qin, Y., Wang, J., and Wei, C., "Joint pricing and inventory control for fresh produce and foods with quality and physical quantity deteriorating simultaneously," International Journal of Production Economics, vol. 152, pp. 42-48, 2014/06/01/ 2014.

Salemdeeb, R., zu Ermgassen, E. K., Kim, M. H., Balmford, A., and Al-Tabbaa, A., "Environmental and health impacts of using food waste as animal feed: a comparative analysis of food waste management options," Journal of Cleaner Production, vol. 140, pp. 871-80, 2017a.

Salemdeeb, R., zu Ermgassen, E. K. H. J., Kim, M. H., Balmford, A., and Al-Tabbaa, A., "Environmental and health impacts of using food waste as animal feed: a comparative analysis of food waste management options," Journal of Cleaner Production, vol. 140, pp. 871-80, 2017/01/01/ 2017 b.

Schneider, F. "Review of food waste prevention on an international level." In Proceedings of the Institution of Civil Engineers-Waste and Resource Management, 187-203. ICE Publishing. 2013.

Sgarbossa, F., and Russo, I., "A proactive model in sustainable food supply chain: Insight from a case study," International Journal of Production Economics, vol. 183, pp. 596-606, 2017.

Soysal, M., Bloemhof-Ruwaard, J., and Van der Vorst, J., "Modelling food logistics networks with emission considerations: The case of an international beef supply chain," International Journal of Production Economics, vol. 152, pp. 57-70, 2014.

Soysal, M., Bloemhof-Ruwaard, J. M., Meuwissen, M. P., and van der Vorst, J. G., "A review on quantitative models for sustainable food logistics management," International Journal on Food System Dynamics, vol. 3, no. 2, pp. 136$55,2012$.

Thi, N. B. D., Kumar, G., and Lin, C.-Y., "An overview of food waste management in developing countries: Current status and future perspective," Journal of Environmental Management, vol. 157, pp. 220-29, 7/1/2015.

Thyberg, K. "Food Waste and Sustainability: Quantifying Food Waste Disposal and Evaluating the Environmental Impacts of Technologies and Policies." In, edited by Tonjes, Damgaard, Ferguson, Gurevitch and Walker. ProQuest Dissertations Publishing. 2015.

Thyberg, K. L., and Tonjes, D. J., "Drivers of food waste and their implications for sustainable policy development," Resources, Conservation \& Recycling, vol. 106, pp. 110-23, 2016.

Weber, C. L., and Matthews, H. S., "Food-miles and the relative climate impacts of food choices in the United States," 2008. 


\section{Biographies}

Adel W. Fadhel is a lecturer of Industrial Engineering in the department of Systems and Industrial Engineering at King Fahd University of Petroleum and Minerals (KFUPM), Dhahran, Saudi Arabia. He is a Ph.D. candidate in the department of Mechanical and Industrial Engineering at Northeastern University, Massachusetts, USA. He earned B.S. in Industrial Engineering, B.S. in Mathematics, Masters in Industrial and Systems Engineering from KFUPM. He has published conference papers. His research interests include supply chain engineering, data analysis, operations management, optimization, simulation, facility planning, sustainability, and food supply chain.

Surendra M. Gupta is a Professor of Mechanical and Industrial Engineering and the Director of the Laboratory for Responsible Manufacturing at Northeastern University in Boston, Massachusetts, USA. He received his BE in Electronics Engineering from Birla Institute of Technology and Science, MBA from Bryant University, and MSIE and $\mathrm{Ph} . \mathrm{D}$. in Industrial Engineering from Purdue University. He is a registered professional engineer in the State of Massachusetts, USA. Dr. Gupta's research interests span the areas of Production/Manufacturing Systems and Operations Research. He is mostly interested in Environmentally Conscious Manufacturing, Reverse and Closed-Loop Supply Chains, Disassembly Modeling and Remanufacturing. He has authored or coauthored twelve books and well over 600 technical papers published in edited books, journals and international conference proceedings. His publications have received over 14,500 citations (with an h-index of 61) from researchers all over the world in journals, proceedings, books, and dissertations. He has traveled to all seven continents viz., Africa, Antarctica, Asia, Australia, Europe, North America and South America and presented his work at international conferences on six continents. In addition, he has delivered keynote speeches in international conferences in several countries including Spain, The Netherlands, Denmark, France, Japan, Korea, Thailand, India, Taiwan, China, Saudi Arabia and Turkey. Dr. Gupta has taught over 150 courses in such areas as operations research, inventory theory, queuing theory, engineering economy, supply chain management, and production planning and control. Among the many recognitions received, he is the recipient of outstanding research award and outstanding industrial engineering professor award (in recognition of teaching excellence) from Northeastern University, international distinguished professor award as well as a national outstanding doctoral dissertation advisor award. 